\title{
Natural rubber/graphene oxide composites: Effect of sheet size on mechanical properties and strain- induced crystallization behavior
}

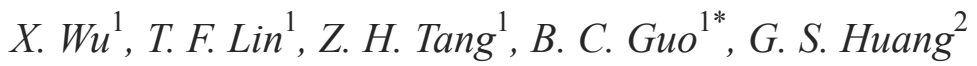 \\ ${ }^{1}$ Department of Polymer Materials and Engineering, South China University of Technology, 510640 Guangzhou, People's \\ Republic of China \\ ${ }^{2}$ College of Polymer Science and Engineering, State Key Laboratory of Polymer Materials Engineering, Sichuan \\ University, 610065 Chengdu, People's Republic of China
}

Received 10 November 2014; accepted in revised form 1 February 2015

\begin{abstract}
In order to analyze the influence of the lateral size of graphene oxide (GO) on the properties of natural rubber/ graphene oxide (NR/GO) nanocomposites, three different sized graphene oxide sheets, namely G1, G2 and G3 were used to fabricate a series of NR/GO nanocomposites by latex mixing. The results indicate that adding GO can remarkably increase the modulus of NR. The enhancement of modulus is strongly dependent on the size of GO sheets incorporated. G1 with smallest sheet size gives the maximum reinforcement effect compared with G2 and G3. Dynamic mechanical measurement and swelling ratios $\left(Q_{\mathrm{f}} / Q_{\mathrm{g}}\right)$ indicate that G1 has stronger interfacial interaction with NR. XRD shows G1 is more effective in accelerating the strain-induced crystallization (SIC) of NR. The strong interfacial interaction facilitates the stress transfer and strain-induced crystallization, both of which lead to the improved modulus.
\end{abstract}

Keywords: nanocomposites, size effect, natural rubber, SIC, graphene oxide

\section{Introduction}

Nowadays, rubber technology has become an important part in industry; nevertheless, the low strength and modulus limit its applications in many cases. So, it needs to be filled with various fillers to achieve optimum properties for practical purposes. Among a variety of reinforcing fillers, graphene (GE) as a new type of nanofiller has attracted increasing interest since it has a thin-layered 2D structure, high specific surface area, excellent mechanical properties, thermal properties and electrical properties [1-3]. The excellent mechanical properties of the natural rubber would be attributed to strain-induced crystallization (SIC) [4-6]. The reinforcement effect of filler on NR is variously attributed to 'strain amplification' and 'stress transfer' through the filler net- work [7-9]. Nanofillers are of remarkable influence on the strain-induced crystallization of NR because of their strong interfacial interaction with polymer matrix [10]. The introduction of filler in NR changes the stress field, increases the local strain of the chain, makes SIC to start at a lower strain, which is called 'strain amplification' [11]. In order to obtain high effective reinforcement, a sufficient load transfer from polymer to reinforcing fillers is required. On application of an external stress, the polymer matrix undergoes greater strain than the filler, resulting in shear stresses at the polymer-filler interfaces [12]. The matrix shear stress increases with the external stress and is transferred to the fillers until the failure of the filler-polymer interfaces. Strong interfaces are able to support large interfacial stresses and pro-

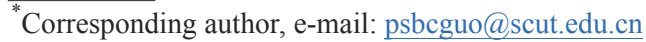
(C) BME-PT
} 
duce excellent mechanical properties of the composites.

As a precursor of graphene, GO also exhibits high strength and modulus $[13,14]$. Due to its excellent hydrophilicity and the availability of a latex form for most rubbers, GO can be incorporated into rubbers via the latex co-coagulation process for reinforcement [15]. As for examples, Kang et al. [16] reported that with 1.9 vol\% GO, the tensile strength and tear strength of carboxylated acrylonitrile butadiene rubber/graphene oxide (XNBR/GO) increased by 357 and $117 \%$, respectively. There is hydrogen bonding between $\mathrm{GO}$ and XNBR, since both contain many oxygen-containing groups. Hence, the strong interfacial interactions would promote the dispersion of GO and facilitate the load transfer from $\mathrm{XNBR}$ to the GO sheets. Moghaddam et al. [17] prepared NR/rGO nanocomposites by thermodynamically favorable self-assembly of GO at oil-water interfaces and found improvements in the modulus and ultimate strength of the nanocomposites. Mao et al. [18] prepared styrene-butadiene rubber (SBR)/GO nanocomposites by combined latex compounding and spray drying. With $5 \mathrm{phr}$ GO, the composite exhibited 7.8 times higher modulus at $300 \%$ strain and 6.4 times higher tensile strength compared with the pure SBR.

It is well known that the filler size is an important factor that determines the overall performances of the resulting nanocomposite, but there are rarely reports concerning the size effect of graphene. Wang et al. [19] prepared SBR composites with different size of fillers and found that the fillers with smaller size exhibited higher reinforcing efficiency towards SBR as they could reach so-called critical particleparticle distance for reinforcement at lower filler content. But the tensile strength was almost unchanged when the filler size became small enough. Khan et al. [20] found that as the flake size of graphene decreased, the Young's modulus of polyurethane/ graphene composites fell dramatically while the ultimate tensile strength and the strain at break rose slightly. Choi et al. [21] reported that functionalized graphene sheets (FGS) with a larger particle size have better reinforcement in 5\% secant modulus of thermoplastic polyurethane/functionalized graphene sheets nanocomposites, but lower in tensile strength and elongation at break. He proposed that the stress transfer from matrix polymer to dispersed FGS will be more effective when the aspect ratio of the filler is larger. Chatterjee et al. [22] studied the influence of graphene nanoplatelets ( $\mathrm{GnPs}$ ) size on composite properties, pointed that the bigger size of graphene nanoplatelets resulted in greater reinforcement of fracture toughness and flexural modulus for epoxy resin at all GnPs concentrations. He ascribed this to the higher aspect ratio and load transfer efficiency of larger size GnPs. Wang et al. [23] got an opposite conclusion, he studied the mechanism of graphene oxide toughening epoxy and suggested that graphene oxide with smaller sheet size were highly effective in resisting crack propagation and gave the maximum reinforcement effect in fracture toughness compared with larger ones. These contradictory results may be due to the fact that the properties of polymer composites are affected by multi-factors including filler types and dispersion, filler-polymer interaction, and polymer matrices [24-26]. Herein, the graphene and matrix types as well as the nanocomposite manufacturing technique account for the discrepancies [27]. So far, although a few studies on polymer/ graphene composites have been made, some questions still remain.

Considering that NR is a strategically important material with unique SIC behavior and the NR/GO composites are widely reported, the effects of GO size on the properties of the composites are generally ignored. Herein, we prepare a series of NR/GO nanocomposites filled with different GO sizes through latex co-coagulation technology, and aim to evaluate the effect of GO size on the mechanical properties of NR/GO nanocomposites and discuss its influence on SIC of natural rubber.

\section{Experimental}

\subsection{Materials}

NR latex ( $60 \mathrm{wt} \%$ of NR content) was obtained from the China Hainan Rubber Industry Group Co., Ltd. Three sizes of graphite flakes were purchased from Qing Dao JinRiLai Graphite CO. Ltd (China). Their average size is 10000,325 and 50 mesh, respectively. The reagents including concentrated sulfuric acid $\left(\mathrm{H}_{2} \mathrm{SO}_{4}\right)$, hydrochloric acid $(\mathrm{HCl})$, calcium chloride $\left(\mathrm{CaCl}_{2}\right)$, potassium permanganate $\left(\mathrm{KMnO}_{4}\right)$ and sodium nitrate $\left(\mathrm{NaNO}_{3}\right)$ were analytically pure and commercially available. All the rubber ingredients were industrial grade and used as received. 


\subsection{Preparation of graphite oxide}

Graphite oxide was prepared by oxidizing natural graphite powder (or expanded graphite) based on a modified Hummers method [28]. Typically, $10 \mathrm{~g}$ of graphite powder (or expanded graphite) and $5 \mathrm{~g}$ of $\mathrm{NaNO}_{3}$ were added into $230 \mathrm{~mL}$ of concentrated $\mathrm{H}_{2} \mathrm{SO}_{4}$ in an ice bath. Under vigorous stirring, $30 \mathrm{~g}$ of $\mathrm{KMnO}_{4}$ was gradually added within $1 \mathrm{~h}$. The mixture was then stirred at $35^{\circ} \mathrm{C}$ for $0.5 \mathrm{~h}$, followed by diluting with $460 \mathrm{~mL}$ of deionized (DI) water. The temperature of the mixture was maintained at $90^{\circ} \mathrm{C}$ for $15 \mathrm{~min}$. The reaction was terminated by adding $1400 \mathrm{~mL}$ of DI water and $25 \mathrm{~mL}$ of $\mathrm{H}_{2} \mathrm{O}_{2}$ aqueous solution $(30 \%)$. The obtained graphite oxide slurry was filtered and washed with diluted $\mathrm{HCl}$ aqueous solution to remove metal ions. Finally, the product was washed with DI water repeatedly until it was neutral. The obtained graphite oxide was then exfoliated in water via sonication to form GO suspension. The GO powder was denoted as G1, G2 and G3 according to different size of GO sheets.

The graphite flakes with the size of 10000 and 325 mesh were directly oxidized. The graphite flakes with the size of 50 mesh were thermally expanded before oxidizing for their strong interlayer interactions. Natural graphite flakes (50 mesh) and sulfuric acid were mixed and then nitric acid was added into the mixture. After magnetic stirring for $24 \mathrm{~h}$, the mixture was washed with DI water to neutral and dried to obtain graphite intercalation compound (GIC). The dry GIC powder was expanded in a microwave oven for 20 second to obtain expanded graphite (EG).

\subsection{Preparation of NR/GO composites}

A desired amount of GO suspension was added into the NR latex and stirred to produce homogeneous mixtures. After $1 \mathrm{~h}$ stirring, the resulting mixture was co-coagulated by adding $\mathrm{CaCl}_{2}(1.0 \mathrm{wt} \%)$ aqueous solutions as the flocculating agents. The co-coagulated compounds were washed with de-ionized water several times until no chloride ion was detected. After that, the compounds were vacuum dried at $50^{\circ} \mathrm{C}$ over night. Then the dried compounds were compounded with rubber ingredients with a two-roll mill and subjected to compression at $150^{\circ} \mathrm{C}$ for the optimum curing time determined by the U-CAN UR2030 vulcameter. The formulation of the composite is as follows: NR $100 \mathrm{phr}$, sulfur $2 \mathrm{phr}$, ZnO $5 \mathrm{phr}$, CZ 0.9 phr, stearic acid $1 \mathrm{phr}$ and 4010NA $1 \mathrm{phr}$ (where phr means parts per 100 parts of rubber).

\subsection{Characterization}

To measure the size of GO sheets, the GO droplets were applied on the silicon wafer and dried to take clear images of GO under scanning electron microscope (SEM) (FESEM, Hitachi S-4800). The cross section of tensile fractured surfaces after tensile test was examined by SEM. Before testing, these samples were sputter coated with $\mathrm{Au}$. The measurement of the mechanical properties was conducted on a universal testing machine (GOTECH AI-7000S, Taiwan) at room temperature with a cross-head speed of $500 \mathrm{~mm} / \mathrm{min}$. X-ray photoelectron spectroscopy (XPS) analysis was carried out on a Kratos Axis Ultra DLD with Al Ka radiation $(1486.6 \mathrm{eV})$. X-ray diffraction (XRD) analysis was performed using an $X$ 'pret Pro diffractometer (Panlytical, Netherlands). The X-ray beam was $\mathrm{Cu} \mathrm{Ka}(\lambda=0.1548 \mathrm{~nm})$ radiation operated at $40 \mathrm{kV}$ and $40 \mathrm{~mA}$. The samples at different strain ratio were fixed in a homemade fixture and scanned for the XRD tests.

Dynamic mechanical properties were determined by a dynamic mechanical analyzer Q800 (TA Instrument, Inc., USA). The tests were carried out at frequency of $1 \mathrm{~Hz}$, strain $0.01(1 \%)$, temperature range -100 to $+30^{\circ} \mathrm{C}$ with a heating rate of $3^{\circ} \mathrm{C} / \mathrm{min}$ under tensile mode. The strain sweep experiments were conducted in a strain range of $0.01-200 \%$ at $60^{\circ} \mathrm{C}$ under $1 \mathrm{~Hz}$ using RPA2000 rubber process analyzer (Alpha Technologies Co., Akron, USA). The samples used in the RPA measurement were the unvulcanized compounds containing curing additives.

The rubber-filler interaction was determined using Park and Lorenz equation [29] (Equation (1)):

$$
\frac{Q_{\mathrm{f}}}{Q_{\mathrm{g}}}=a \mathrm{e}^{-\mathrm{z}}+b
$$

where the subscripts $f$ and $g$ refer to filled and gum vulcanizates, respectively; $z$ is the ratio by weight of the filler to the rubber hydrocarbon in the vulcanizates; and $a$ and $b$ are constants. $Q_{\mathrm{f}}$ and $Q_{\mathrm{g}}$ are the toluene uptake per gram of filled and gum vulcanizates, respectively, which are measured as following. The cured sample is immersed in toluene until equilibrium swelling for $48 \mathrm{~h}$ at $25^{\circ} \mathrm{C}$. The samples 
were dried in an oven at $60^{\circ} \mathrm{C}$ until constant weights were obtained. The toluene uptake per gram of rubber $(Q)$ was determined using Equation (2):

$Q=\frac{W_{\mathrm{s}}-W_{\mathrm{d}}}{W_{0} \cdot \varphi}$

where $W_{\mathrm{s}}$ is the swollen weight, $W_{\mathrm{d}}$ is the dried weight, $W_{0}$ is the original weight, and $\varphi$ is the mass fraction of the rubber in the composites.

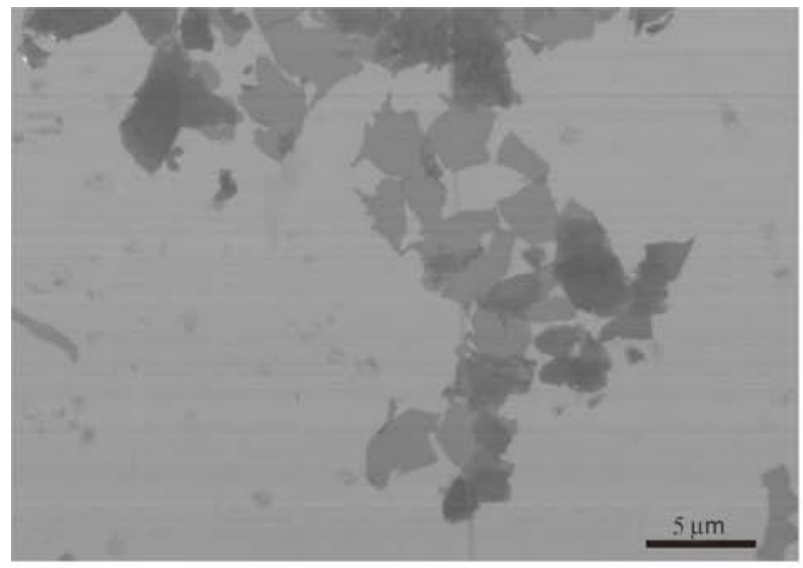

a)

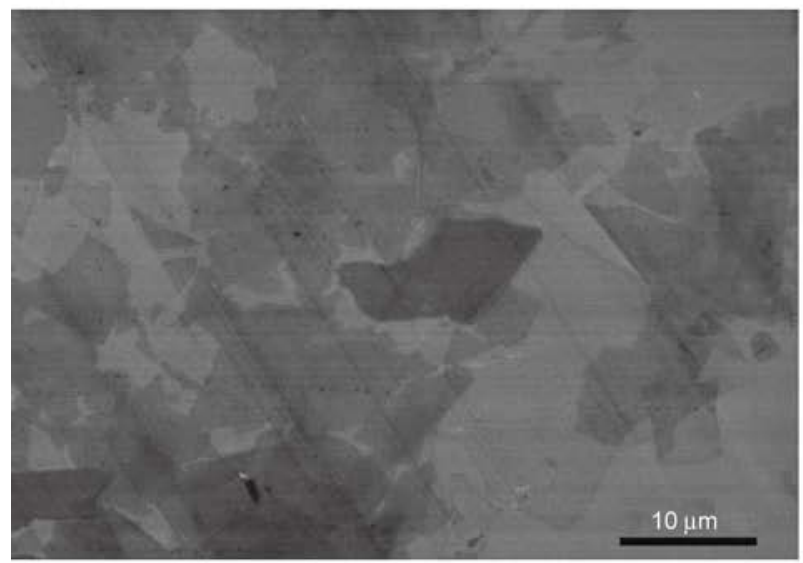

c)

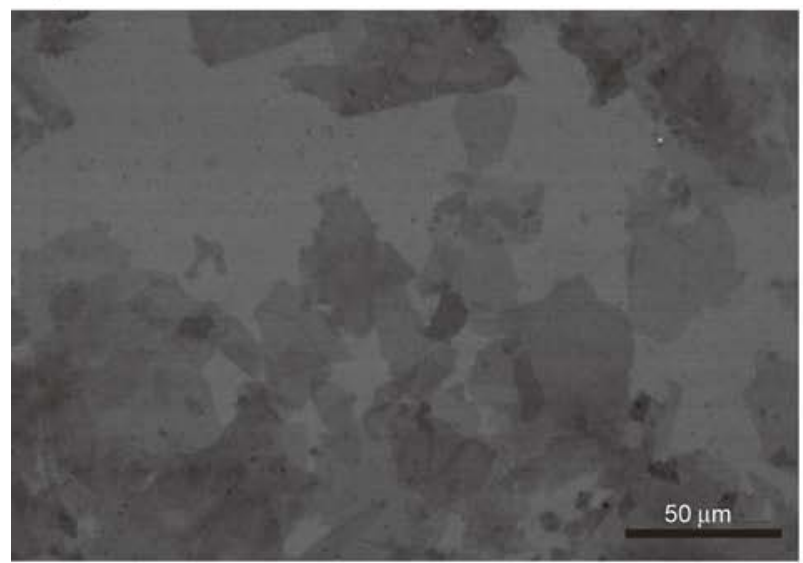

e)

\section{Results and discussion}

\subsection{Characterization of three types of GO} sheets

There are various factors which would affect the size of GO sheets, such as degree of oxidation [30, 31], controlled centrifugation [32], $\mathrm{pH}$ value [33], shaking or sonication [34]. Unfortunately, these methods are not suitable for mass production due to their low yield. So the large scale production of high-

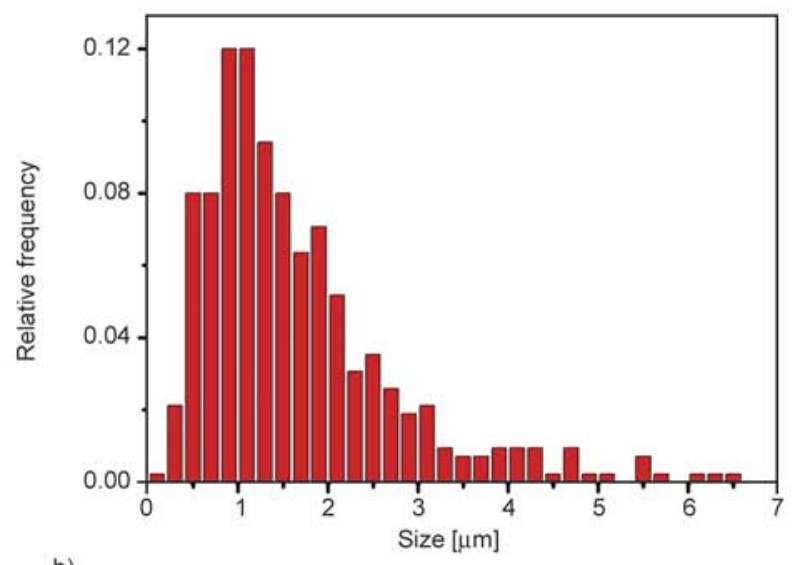

b)

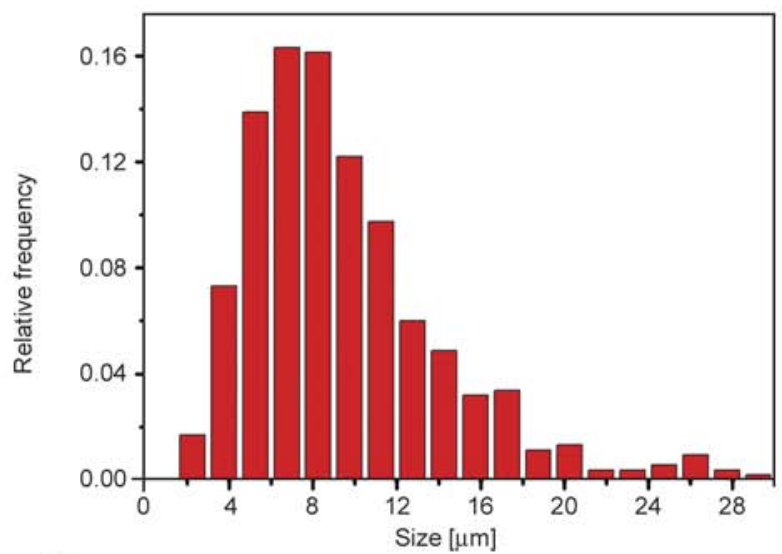

d)

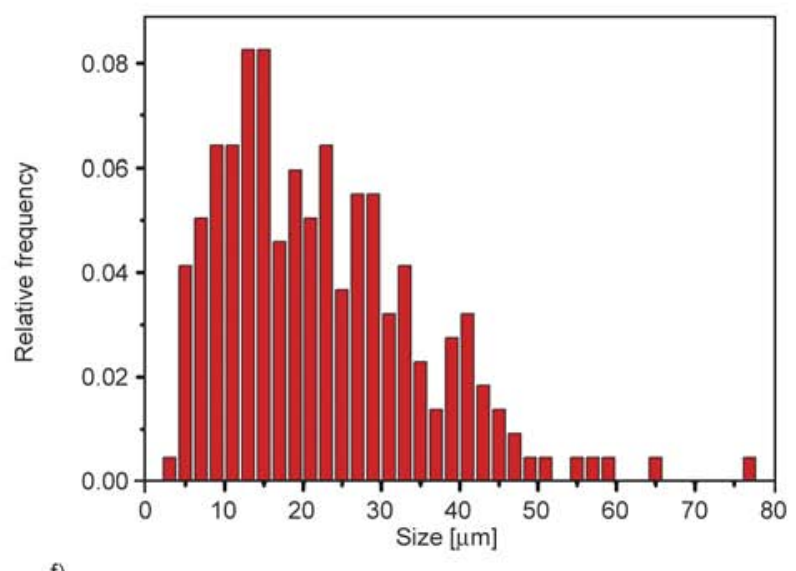

Figure 1. Typical SEM images of (a) G1, (c) G2, (e) G3, and the histograms for the size distribution of (b) G1, (d) G2, (f) G3 
quality GO sheets with controlled size still remains a significant challenge. According to Zhou and Liu's [35] study, the size of the exfoliated GO sheets are closely associated with those of the starting graphite flakes. In this paper, a simple and effective strategy to tune the size of GO sheets was used by selecting suitable starting graphite materials. The average size of three kinds of graphite flakes are 10000,325 and 50 mesh, respectively.

The morphology and size of GO sheets were examined by SEM. Figure 1 presents the SEM images of three types of GO sheets and their corresponding size distributions. The size distributions histograms were obtained based on the measurement of the SEM images for more than 200 sheets for each sample. Obviously, there is an increase in size from G1 to G3. The mean lateral size of G1, G2 and G3 sheets, obtained from the SEM size statistical analysis, are $1.71,9.52$ and $22.44 \mu \mathrm{m}$, respectively.

The surface chemistry of GO sheets is significantly influenced by the GO size. Thus XPS measurements were carried out to analyze the surface chemical composition of the three types of GO sheets in Figure $2 \mathrm{a}$ and the corresponding carbon assignations are summarized in Table 1. The peaks at 284.6, 286.4 and $288.5 \mathrm{eV}$ are assigned to $\mathrm{C}-\mathrm{C}, \mathrm{C}-\mathrm{O}$ and $\mathrm{C}=\mathrm{O}$ functional groups, respectively [36]. The $\mathrm{C} / \mathrm{O}$ atomic ratio is an important parameter for evaluating the degree of oxidation of $\mathrm{GO}$ sheets. It can be seen that there is little change of $\mathrm{C} / \mathrm{O}$ atomic ratio among the three types of GO sheets, showing that the degree of oxidation of them are similar.

The X-ray diffraction (XRD) peaks of three types of GO papers are shown in Figure $2 b$. For all the GO papers, the $2 \theta$ values are around $11^{\circ}$ and the typical

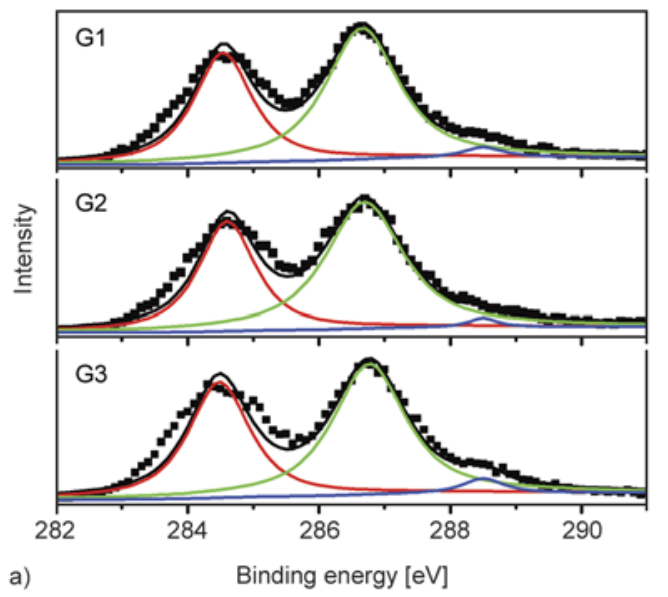

Table 1. Relative atomic percentage of GO sheets of different size

\begin{tabular}{|l|c|c|c|c|}
\hline & $\mathbf{C} / \mathbf{O}$ & $\begin{array}{c}\mathbf{C}-\mathbf{C} \\
{[\mathbf{\%}]}\end{array}$ & $\begin{array}{c}\mathbf{C}-\mathbf{O} \\
{[\mathbf{\%}]}\end{array}$ & $\begin{array}{c}\mathbf{C}=\mathbf{O} \\
{[\mathbf{\%}]}\end{array}$ \\
\hline G1 & 1.95 & 39.3 & 58.26 & 2.42 \\
\hline G2 & 1.81 & 38.39 & 60.07 & 1.54 \\
\hline G3 & 1.86 & 41.26 & 55.33 & 3.4 \\
\hline
\end{tabular}

(002) diffraction peak at $26.5^{\circ}$ for natural graphite has completely disappeared. The interlayer spacing in GO sheets is proportional to the degree of oxidation [30]. The d-spacing between the adjacent GO sheets are 7.68, 8.62 and $7.82 \AA$ for G1, G2 and G3 papers, respectively. The $\mathrm{d}$-spacing is quite consistent with the $\mathrm{C} / \mathrm{O}$ atomic ratio of three types of $\mathrm{GO}$ sheets. Generally, the GO papers with lower $\mathrm{C} / \mathrm{O}$ atomic ratio have higher $\mathrm{d}$-spacing, this can be explained by higher degree of functionalization. The GO sheets with more oxygenated functional groups can absorb more water through hydrogen bonding during film formation, inevitably increasing the interlayer distance to accommodate the water molecules [37].

\subsection{The dispersion state of the GO sheets in the NR/GO nanocomposites}

It is well-known that the dispersion state of the filler and the interfacial interactions are two crucial factors in governing the performance of the composite [17]. The dispersion of the GO sheets in the nanocomposites was characterized by XRD. Figure 3 shows the XRD patterns of NR/GO nanocomposites with 2 phr GO with different sizes. The broad diffraction peak around $20^{\circ}$ is noncrystalline structure of NR, while the diffraction peaks between $30-50^{\circ}$ are assigned to $\mathrm{ZnO}$ particles in the vulcanizates [38].

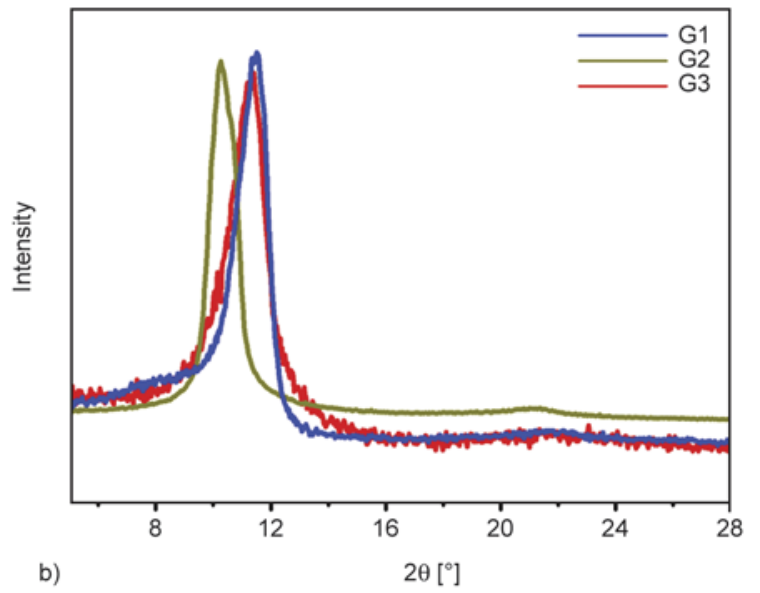

Figure 2. (a) XPS C1s spectra with carbon assignments; (b) XRD patterns of GO sheets of different size 


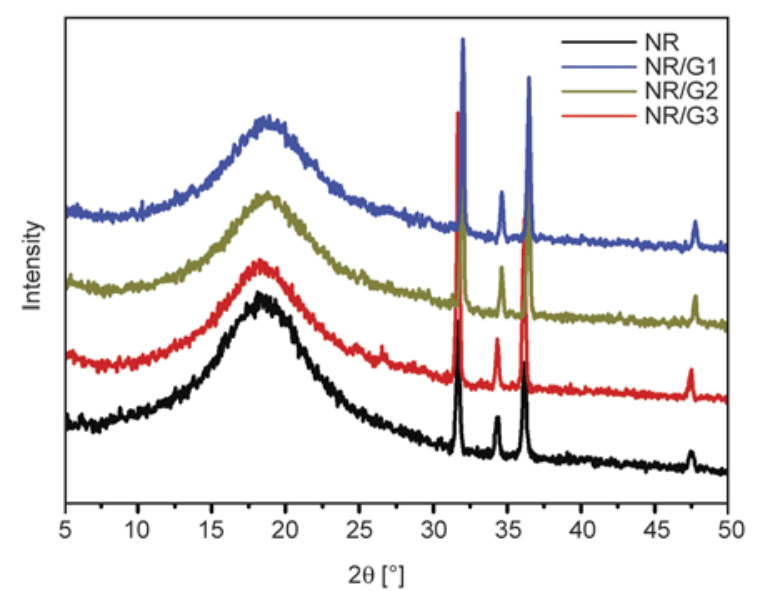

Figure 3. NR/GO nanocomposites with 2 phr GO of different size

All the samples show no obvious characteristic peaks of graphite or GO, indicating that GO sheets are homogeneous dispersed in the polymer matrix and did not show graphite-like ordered structure.

Figure 4 shows the SEM images of the tensile fractured surfaces and TEM images of the NR/GO nanocomposite with $2 \mathrm{phr}$ GO with different size. From the SEM images, it can be seen that GO sheets are well dispersed in the matrix and show no obvious aggregates. The tensile fractured surfaces are rough and no cavities between GO sheets and NR are found. All these indicate strong interfacial interaction between GO and rubber. Furthermore, TEM was used to examine the dispersion of GO in nanocomposites. The dark spots in the pictures are probably the curing agents, since the amount of curing agents are higher than that of GO. Surprisingly, in the TEM images, the GO sheets did not preserve their original length before processing. The lateral sizes of GO sheets in the composites are ranged from dozens to hundreds of nanometers, which are much lower than their original sizes. We measured the size of GO in nanocomposites by carefully inspecting TEM images, this method is developed by Ruoff and coworkers $[39,40]$. In the composites, the mean size of G1, G2 and G3 are 92.68, 164.39 and $323.74 \mathrm{~nm}$, respectively. It is speculated that the milling process break down the GO sheets and lowered the average size of GO due to the dynamic shear force. This is well consistent with other studies [41-44]. It is observed that the G3 with large size show thicker sheets in the NR compared with the thickness of smaller GO sheets, which is likely due to restacking of the sheets during the coagulation process [39].

\subsection{Effects of GO size on the mechanical properties of NR/GO nanocomposites}

Typical stress-strain curves of NR/GO nanocomposites with $2 \mathrm{phr}$ GO having different size are given in Figure 5a. It is evident that the stress of the composites at a given strain is significantly increased with the incorporation of GO and the improvement is more prominent in the composites filled with smaller GO size. Especially, the stress at 300\% strain (modulus), which is an important indicator for the practical applications, of the composites with different GO loading and size are summarized in Figure $5 \mathrm{~b}$. It can be seen that the moduli of all the samples are increased with the addition of GO, and the moduli of the composites are consistently increased with increasing GO loading. The improvement may be explained by several reasons as follows: 1) GO have outstanding mechanical characteristics and higher specific surface area; 2) the distortions and the resultant defects of GO result in a rough and winkled topology on the nanoscale which ensure a strong rubber-to-filler interaction [45]; 3) the interactions between the rubber molecular chains and the GO nanoplatelets can provide additional entanglements or physical crosslinking and GO taking part in the vulcanization reaction can bring chemical crosslinking points according to the tube model [46]; 4) strain-induced crystallization as a substantial feature in mechanical reinforcement of NR specifically at high strain is significantly intensified in the presence of GO layers (as will discussed below) [47].

Comparing the modulus of the composites with different $\mathrm{GO}$ size, it is obvious that the $\mathrm{GO}$ with smaller size shows higher enhancements in the modulus. For example, with the incorporation of $2 \mathrm{phr}$ G1, G2, and G3, the moduli of the corresponding composites increase by 73,53 , and $36 \%$, respectively, with respect to the unfilled NR. Although it is commonly admitted that the graphene with larger size have higher reinforcement as it favors the stress transfer in the composites [20-22]. In this work, it was found that smaller GO sheets show better reinforcement effect. We proposed that properties of the composites are also related to the filler dispersion and interfacial interaction. Considering that the processing method, graphene and polymer types in our work are distinctly different from others', these contradictions can be understood. 


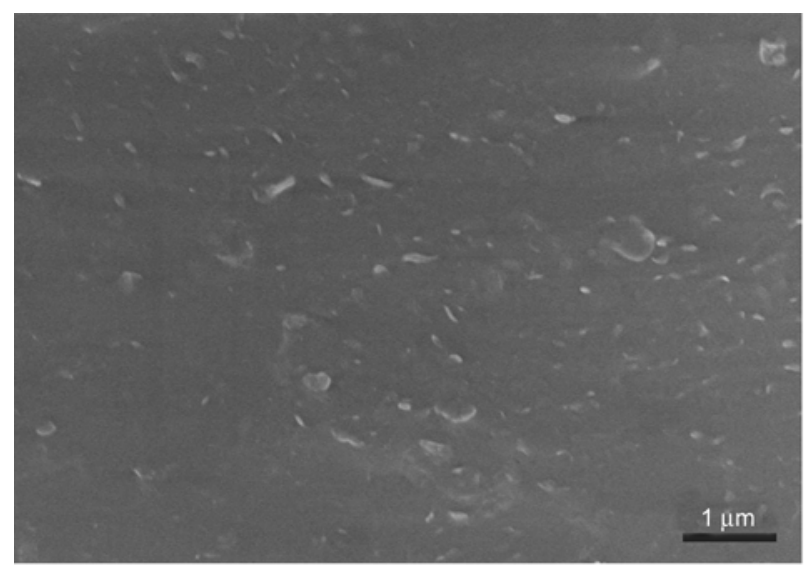

a)

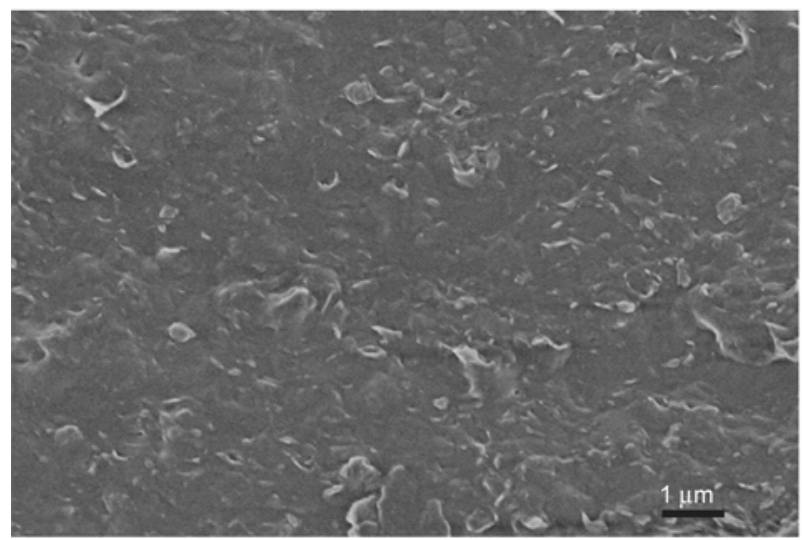

c)

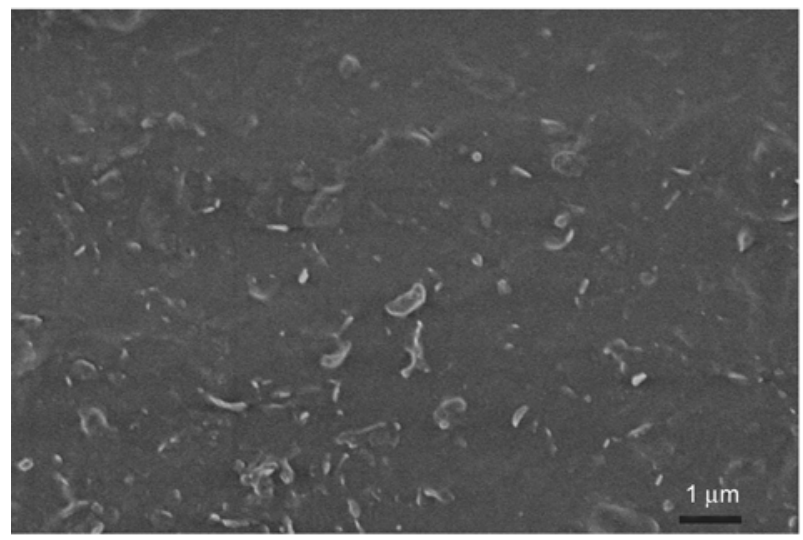

e)

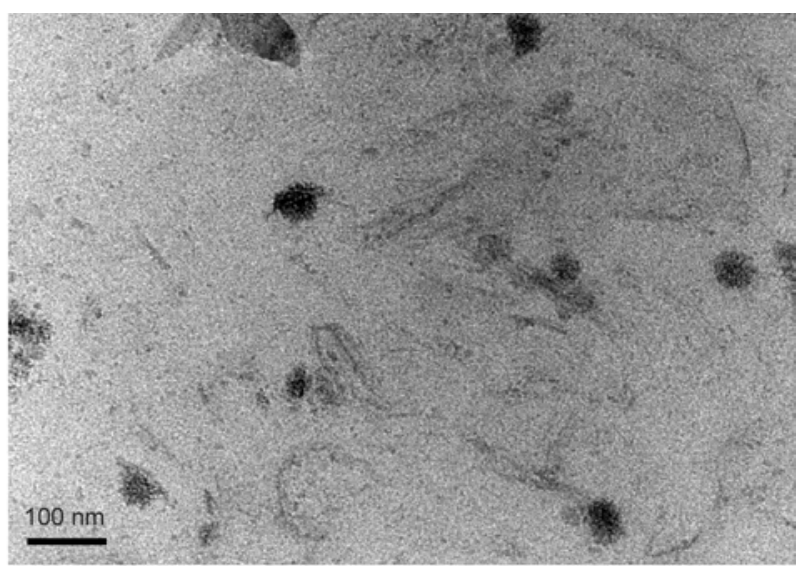

b)

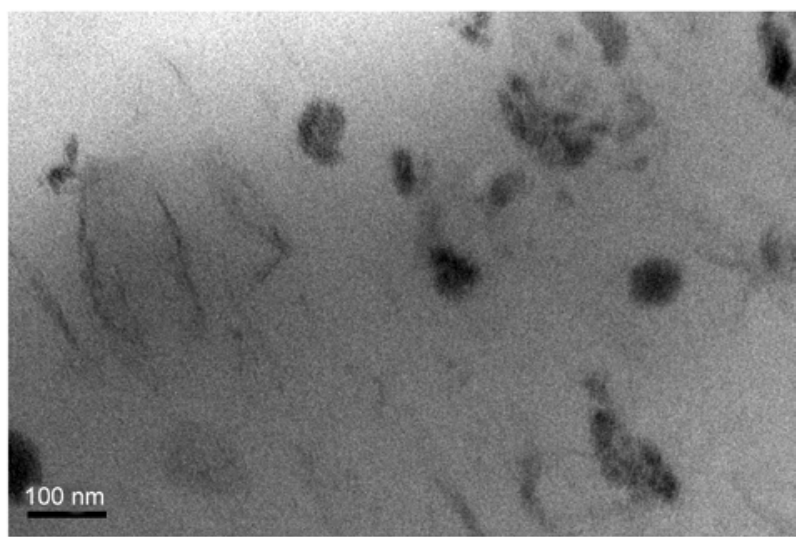

d)

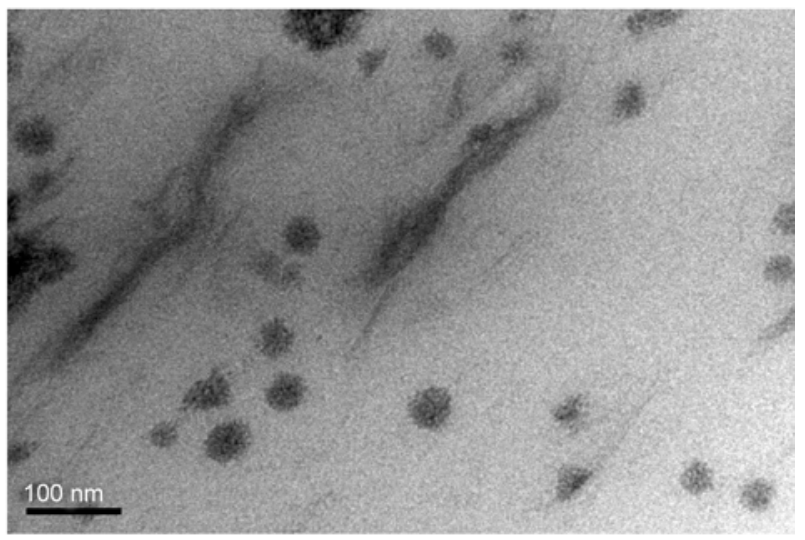

Figure 4. SEM images of the tensile fractured surfaces of (a) NR/G1, (c) NR/G2, (e) NR/G3, and TEM images of (b) NR/G1, (d) NR/G2, (f) NR/G3 nanocomposites with 2 phr GO

It is interesting to find that the elongation at break of NR/GO nanocomposite decreases with decreasing GO size. Previous studies also found that the addition of GO into rubber led to a decrease in the elongation at break of the composites, which is because the movement of the polymer chains is restricted by the interaction between the GO and polymer matrix [16, 48]. Therefore, in our work, it can be understood that GO with smaller size have more number of contacts with NR, which in turn leads to stronger restriction on the rubber chains.
The stress-strain curves are converted into MooneyRivlin plots according to Equation (3):

$$
\sigma^{*}=\frac{\sigma}{\lambda-\lambda^{-2}}=2 C_{1}+2 C_{2} \lambda^{-1}
$$

where $\sigma$ is the applied stress, $\lambda$ is the extension ratio, and $C_{1}, C_{2}$ are the Mooney-Rivlin (MR) constants related to the network and the flexibility of the network chains, respectively. The plots of reduced stress $\left(\sigma^{*}\right)$ against the reciprocal of the extension ratio $(\lambda)$ for $\mathrm{NR} / \mathrm{GO}$ composites with $2 \mathrm{phr} \mathrm{GO}$ are 

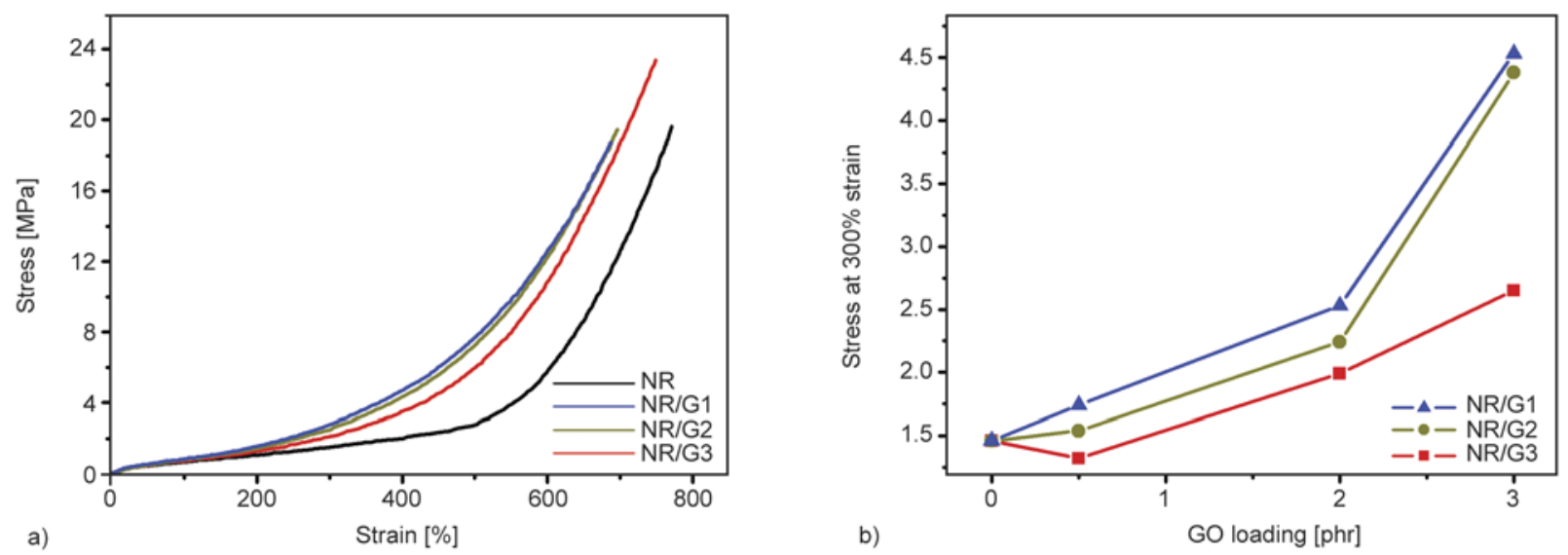

Figure 5. (a) Representative stress-strain curves of NR/GO nanocomposites with 2 phr GO; (b) the effect of GO loading on the stress at $300 \%$ strain

shown in Figure 6. It can be found that $\sigma^{*}$ of all the samples show a large and abrupt upturn at low $\lambda^{-1}$ $\left(\lambda^{-1}<0.3\right)$. Recent studies attributed the abrupt upturn to the strain-induced crystallization [17] and finite extensibility of the polymer chains [16, 49]. With addition of three types of GO, the abrupt upturn shifts to lower extension ratios. This indicates that

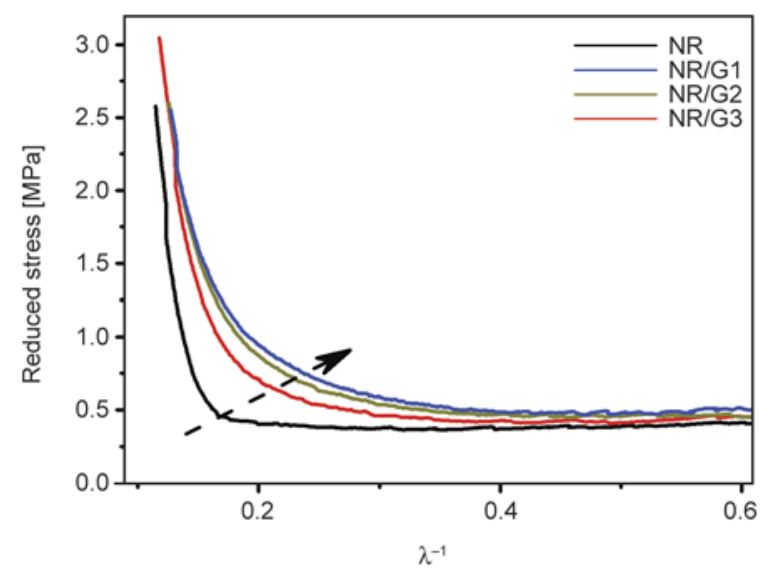

Figure 6. Reduced stress as function of $\lambda^{-1}$ (Mooney-Rivlin plots) of NR/GO nanocomposites with $2 \mathrm{phr} \mathrm{GO}$

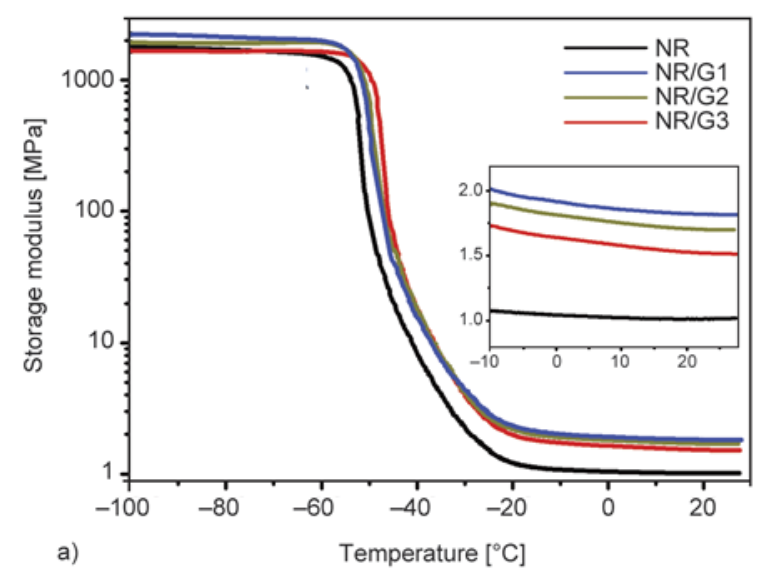

the addition of GO layers facilitates the crystallization of NR during stretching. The abrupt upturn in the curves shifts to lower extension ratio with decreasing the GO size. This means that GO with smaller size is more effective in accelerating the SIC of NR than larger ones, which will discussed in detail later.

In an attempt to compare the reinforcing efficiency of three types of GO on the performance of the composites, DMA measurements are performed. Figure 7 is the temperature dependence of the storage modulus $\left(E^{\prime}\right)$ and $\operatorname{loss}$ factor $(\tan \delta)$ of the NR/GO composites with $2 \mathrm{phr}$ GO. The dynamic properties reflect the amount of the energy in the composite stored as elastic energy and the amount of energy dissipated during the strain process. These properties are highly dependent on the existence of fillers: dispersion within the matrix, volume fraction, geometrical characteristics, and load transfer from the filler to the matrix [50]. As illustrated in Figure 7a, G1 and G2 give an increase in $E^{\prime}$ in both the rubbery region and glassy region, $\mathrm{G} 3$ only in the

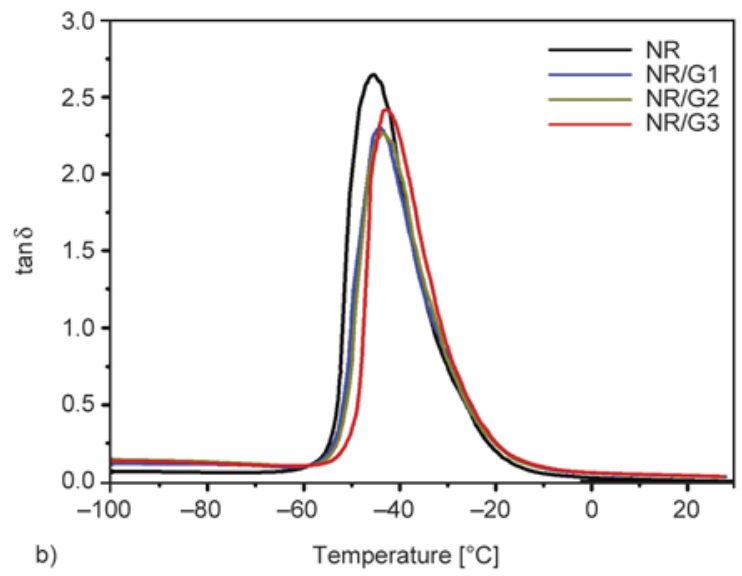

Figure 7. Storage modulus (a) and loss factor (b) versus temperature for NR and NR/GO nanocomposites with 2 phr GO 
rubbery region. For instance, at $20^{\circ} \mathrm{C}$ the storage modulus of the NR and the composites with G1, G2 and $\mathrm{G} 3$ are 1.01, 1.82, 1.71 and $1.52 \mathrm{MPa}$, respectively. In the rubbery region, the storage modulus enhancement is in the order of the $\mathrm{NR}<\mathrm{NR} / \mathrm{G} 3<$ $\mathrm{NR} / \mathrm{G} 2<\mathrm{NR} / \mathrm{G} 1$. The reinforcement can be explained by the relative stiffness of the filler and the matrix in rubbery and glassy phases $[51,52]$. In the DMA test, the strain was only $1 \%$ and do not initiate straininduced crystallization of NR. The storage modulus of the composite is mainly affected by the stress transfer from rubber to filler, which is in direct correlation with the interfacial interaction between the NR and GO sheets.

As observed from Figure 7b, the glass transition temperature $\left(T_{\mathrm{g}}\right)$ of the composites taken at the maximum value of the $\tan \delta$ are $-45.5,-44.2,-43.5$, $-42.4^{\circ} \mathrm{C}$ for NR and the composites with G1, G2 and G3, respectively. The glass transition temperature $\left(T_{\mathrm{g}}\right)$ of the composites represents the mobility of polymer chains. The adsorption of polymer chains to the rigid particles can slow down the polymer dynamics, which consequently may increase the $T_{\mathrm{g}}$ of the polymer chains in filler-polymer interfaces. However, some published literatures show increases in the $T_{\mathrm{g}}$ of the bulk polymer chains upon the addition of GO or graphene [53,54], while others report no obvious change in $T_{\mathrm{g}}[39,47,55]$ or even decrease in $T_{\mathrm{g}}$ [49]. A very recent study shows that only the covalent attachment of polymer chains onto graphene surface can produce significant restriction on the mobility of the bulk polymer and lead to an increase in the $T_{\mathrm{g}}$ [56]. In our work, the variation of $T_{\mathrm{g}}$ is in a very narrow region of $1-3^{\circ} \mathrm{C}$, which may be considered to be essentially the same.

The maximum $\tan \delta$ values of NR decrease with the incorporation of GO. The decrease of $\tan \delta$ peak reflects that $\mathrm{GO}$ sheets have effectively immobilized NR chains near the polymer-particle interface due to favorable interfacial interactions with the NR matrix $[39,57]$. Meanwhile, the maximum $\tan \delta$ values of the composites with G2 and G1 are lower than that of G3. This result indicates that GO with smaller size have stronger interfacial interaction with rubber. In general, when the GO mixed with rubber, a glassy layer in the vicinity of the GO sheets is formed by adsorbing rubber chains onto the GO surface [58]. Smaller GO sheets are thinner in the rubber matrix, which increases the contact area with rubber.

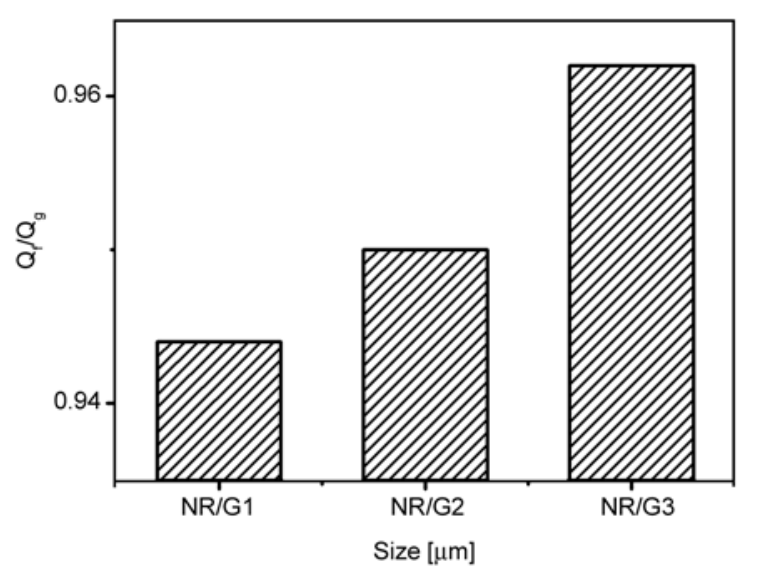

Figure 8. The effect of GO size on filler-rubber interaction of $\mathrm{NR} / \mathrm{GO}$ composites with $2 \mathrm{phr}$ GO

The effect of the GO size on the rubber-filler interaction in the NR/GO nanocomposites is shown in Figure 8 . The value of $Q_{\mathrm{f}} / Q_{\mathrm{g}}$ is increasing with increasing GO size. The lower $Q_{\mathrm{f}} / Q_{\mathrm{g}}$ values mean a higher extent of the interaction between the filler and the rubber matrix. Because of the forming of glassy layer, there were less empty spaces or voids in the matrix, thus less solvent get absorbed and the $Q_{\mathrm{f}} / Q_{\mathrm{g}}$ values would decrease [59]. The composite with G1 gave the lowest $Q_{\mathrm{f}} / Q_{\mathrm{g}}$ value, which indicated strongest filler-rubber interaction.

Figure 9 displays the strain amplitude dependence of storage modulus $\left(G^{\prime}\right)$ of NR/GO nanocomposites. Payne effect is mainly related to the breakdown of physical filler networks formed by filler-filler interactions and filler-rubber interactions upon application of oscillatory shear [16]. At low strain range, the applied shear stress is not able to break the network of GO, forming a plateau of nearly constant storage modulus; with further increase in strain

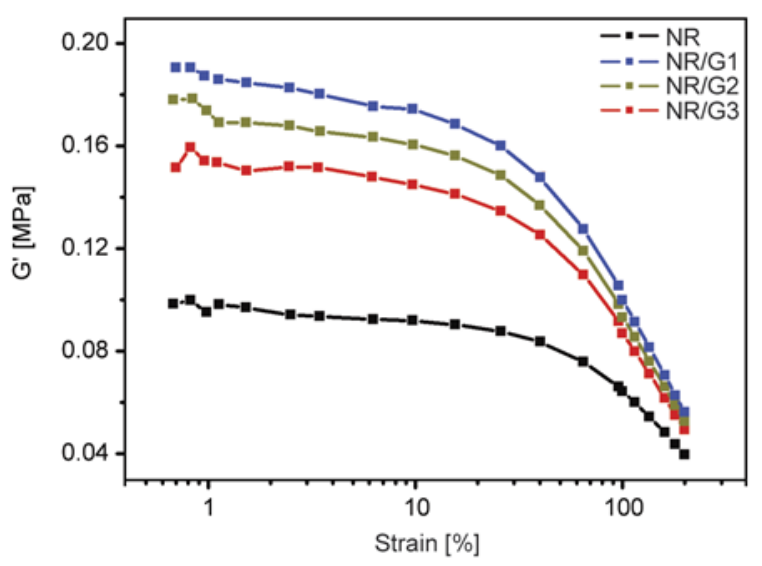

Figure 9. Storage modulus versus strain for NR/GO nanocomposites with $2 \mathrm{phr}$ GO of different size 
amplitude the filler-filler interaction destructs, leading to an abrupt decrease of modulus. The Payne effect is denoted by $\Delta G^{\prime}=G_{0}-G_{\infty}$ (we note $G_{0}$ the initial modulus at $0.68 \%$ strain and $G_{\infty}$ the infinite modulus at $200 \%$ strain) [60,61]. The $\Delta G^{\prime}$ of the NR and the composites with G1, G2 and G3 are 52.35, 133.43, 131.11 and $117.84 \mathrm{KPa}$, respectively. The highest value of $\Delta G^{\prime}$ appears in nanocomposite with G1, indicating highest Payne effect. In addition, the $G^{\prime}$ for NR/GO compounds also increase with the decreasing GO size. The increased $G^{\prime}$ is attributed to the hydrodynamic effect with the inclusion of rigid filler into the rubber. The NR/GO nanocomposite with G1 shows higher $G^{\prime}$, which is due to the fact that the NR chains trapped or caged into the filler network formed glassy layer and can behave as 'filler' [61].

\subsection{Effects of GO size on strain-induced crystallization of NR}

NR can be subjected to crystallize under stretching, which is a unique characteristic for NR. The crys-

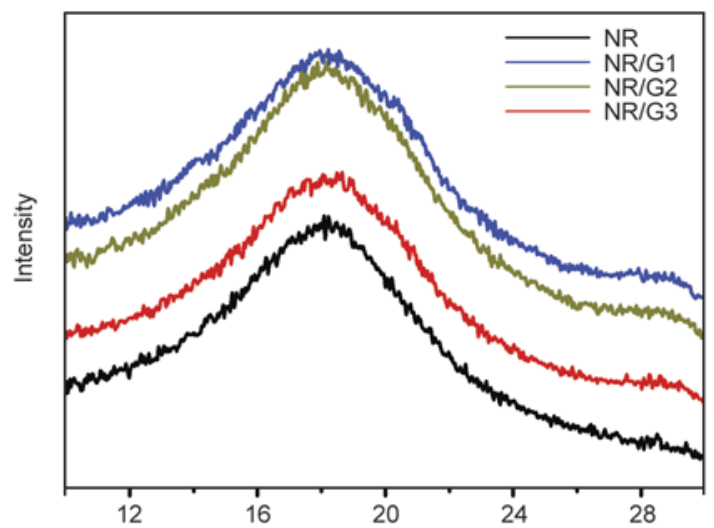

a)

$2 \theta\left[{ }^{\circ}\right]$

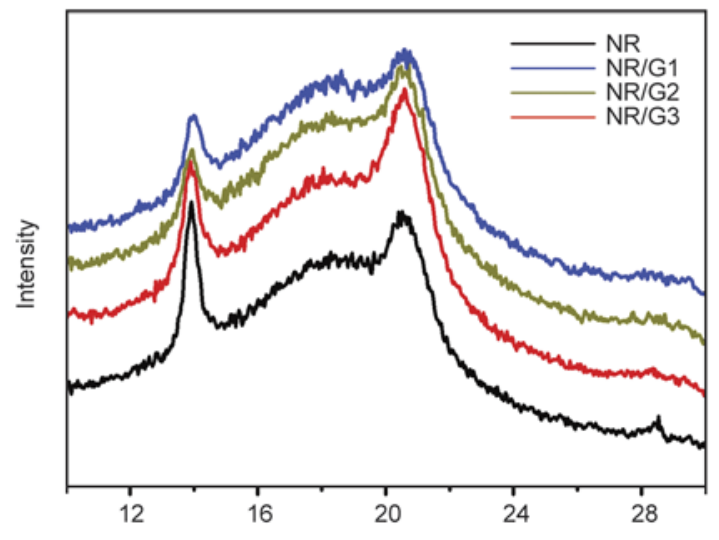

c)

$2 \theta\left[^{\circ}\right]$ tallites act as additional cross-linking points in the network, which account for the obvious enhancements in the mechanical properties of NR. Therefore, it is of great importance to investigate the effect of GO size on the SIC of NR composites. In order to monitor the evolution of strain-induced crystallization, the XRD patterns of NR/GO composites with $2 \mathrm{phr}$ GO at different strains are shown in Figure 10 . The crystallinity index $\left(X_{\mathrm{c}}\right)$ is estimated according to Equation (4) [62]:

$X_{\mathrm{c}}=\frac{A_{\mathrm{c}}}{A_{\mathrm{c}}-A_{\mathrm{a}}} \cdot 100 \%$

where $A_{\mathrm{c}}$ and $A_{\mathrm{a}}$ are the areas of crystalline and amorphous regions, respectively. The crystallinity index of NR and its composites with $2 \mathrm{phr}$ GO at different strains are tabulated in Table 2.

The diffraction peaks near $2 \theta=14$ and $21^{\circ}$ are assigned to the (200) and (120) plane reflections of $\mathrm{NR}$, respectively. The samples did not show crystal diffraction peaks at the strain of $\alpha=2$. However, at $\alpha=3$, two crystalline peaks appear for NR/GO com-

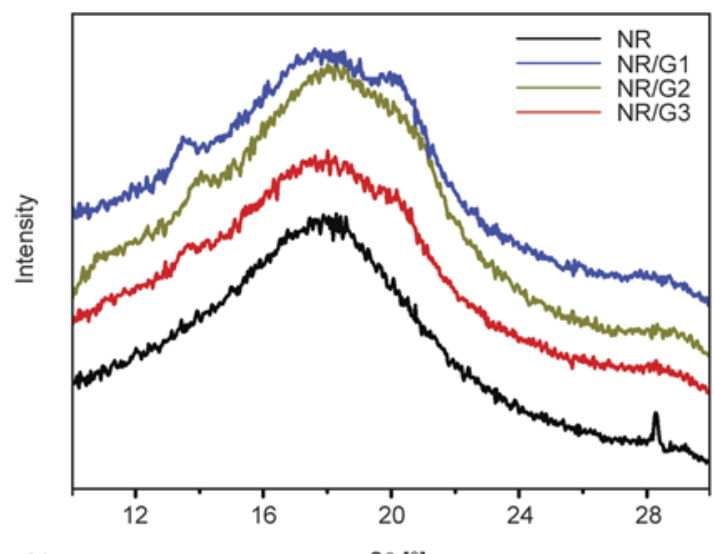

b)

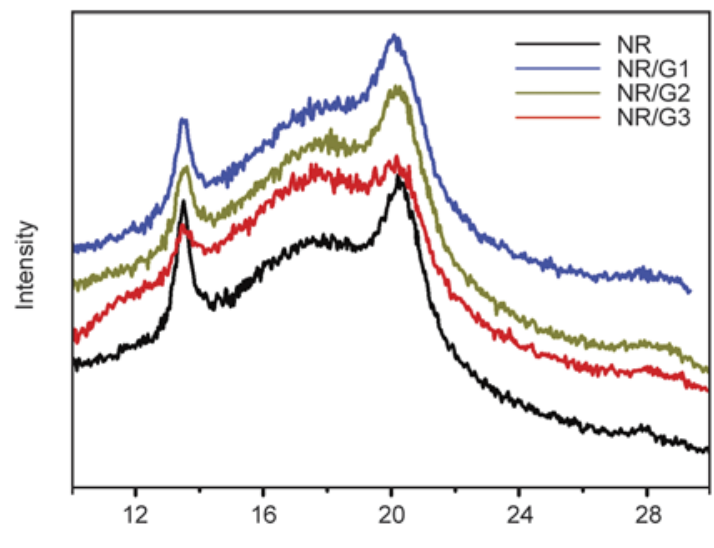

d)

$2 \theta\left[{ }^{\circ}\right]$

Figure 10. The XRD patterns of NR/GO composites with 2 phr GO at different strains (a) $\alpha=2$, (b) $\alpha=3$, (c) $\alpha=4$, (d) $\alpha=5$ 
Table 2. The crystallinity index of NR/GO composites with $2 \mathrm{phr}$ GO at different strains

\begin{tabular}{|l|c|c|c|c|}
\hline & $\begin{array}{c}\boldsymbol{\alpha}=\mathbf{2} \\
{[\mathbf{\%}]}\end{array}$ & $\begin{array}{c}\boldsymbol{\alpha}=\mathbf{3} \\
{[\mathbf{\%}]}\end{array}$ & $\begin{array}{c}\boldsymbol{\alpha}=\mathbf{4} \\
{[\mathbf{\%}]}\end{array}$ & $\begin{array}{c}\boldsymbol{\alpha}=\mathbf{5} \\
{[\mathbf{\%}]}\end{array}$ \\
\hline $\mathrm{NR}$ & 0 & 0 & 21.66 & 25.10 \\
\hline $\mathrm{NR} / \mathrm{G} 1$ & 0 & 10.41 & 24.12 & 24.81 \\
\hline $\mathrm{NR} / \mathrm{G} 2$ & 0 & 7.73 & 22.36 & 24.29 \\
\hline $\mathrm{NR} / \mathrm{G} 3$ & 0 & 3.17 & 24.19 & 24.84 \\
\hline
\end{tabular}

posites due to strain-induced crystallization, while pure NR still shows an amorphous peak. This implies that the inclusion of GO induces the earlier crystallization of NR, which may be ascribe to the strain amplification effect of the filler [63]. The composite with G1 show higher crystallinity index than G2, G3 at $\alpha=3$, revealing that the composite with G1 has a lower onset strain of crystallization. With increasing $\alpha$ to 4 , pure NR starts to crystallize and the difference in crystallinity indexes among different samples are diminished. Furthermore, at $\alpha$ of 5, the crystallinity indexes of all samples are close, indicating that GO sheets could not increase the crystallinity index of NR but facilitate SIC at lower strains. This is well consistent with other studies concerning filler filled NR composites [11, 47].

For two-dimensional nanofillers, for example, nanoclay or graphene, they tend to orient and align parallel to the stretching direction at a very low strain ratio $[9,10,47,64]$. During stretching, the NR chains in the glassy rubber will slip along the GO sheets and form stretching and parallel-arraying straight chain [46]. These early stretched network chains will be acted as crystals nuclei on the basis of the mechanism of crystallization of NR vulcanizate proposed by Tosaka et al. [65] and Toki et al. [4].

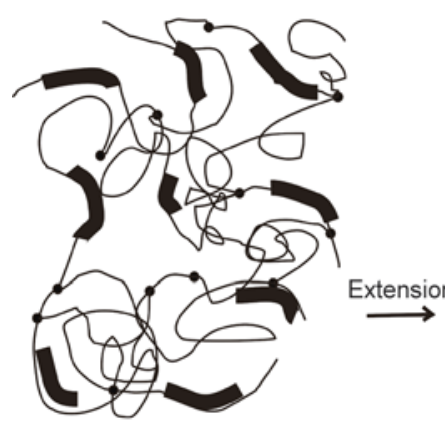

a) GO sheet $\bigcup$ NR chain

b)

- Crosslinking point
Figure 11. Orientation of GO sheets and NR chain duo to extension
Thus, the fact that more polymer chains can be stretched indicates that more nuclei can be formed [66]. As shown in Figure 11, in the initial state most of the GO sheets are dispersed in a random orientation state. Under extension, the NR chains in the glassy layer will slip along the GO sheets at low strain ratio and act as crystals nuclei. In this process, G1 layers having stronger interfacial interaction with NR facilitate alignment and nucleation of NR chains and promote an early onset of the straininduced crystallization.

\section{Conclusions}

NR/GO nanocomposites with three different size GO were prepared through latex mixing method. Incorporation of a small amount of the GO sheets into the NR matrix resulted in a significant improvement on the modulus of the polymer. The enhancement of the modulus is strongly dependent on the size of the GO sheets incorporated. The G1 sheets with smaller size give a better reinforcement effect. GO sheets with smaller size have stronger interfacial interaction with NR and promote stress transfer and strain-induced crystallization, both of which lead to the improved modulus.

\section{Acknowledgements}

This work was supported by National Natural Science Foundation of China (51222301 and 51333003), the Research Fund for the Doctoral Program of Higher Education of China (20130172110001), Key Technologies R\&D Program of Guangzhou City (2013J4300047), and the Fundamental Research Funds for the Central Universities (2014ZG0001).

\section{References}

[1] Vuluga D., Thomassin J-M., Molenberg I., Huynen I., Gilbert B., Jérôme C., Alexandre M., Detrembleur C.: Straightforward synthesis of conductive graphene/polymer nanocomposites from graphite oxide. Chemical Communications, 47, 2544-2546 (2011). DOI: $10.1039 / \mathrm{C} 0 \mathrm{cc} 04623 \mathrm{j}$

[2] Kim H., Abdala A. A., Macosko C. W.: Graphene/ polymer nanocomposites. Macromolecules, 43, 65156530 (2010).

DOI: $10.1021 / \mathrm{Ma1} 100572 \mathrm{e}$

[3] Liu Q., Liu Z., Zhang X., Yang L., Zhang N., Pan G., Yin S., Chen Y., Wei J.: Polymer photovoltaic cells based on solution-processable graphene and $\mathrm{P}_{3} \mathrm{HT}$. Advanced Functional Materials, 19, 894-904 (2009).

DOI: $10.1002 / \mathrm{adfm} .200800954$ 
[4] Toki S., Sics I., Ran S., Liu L., Hsiao B. S., Murakami S., Senoo K., Kohjiya S.: New insights into structural development in natural rubber during uniaxial deformation by in situ synchrotron X-ray diffraction. Macromolecules, 35, 6578-6584 (2002).

DOI: $10.1021 / \mathrm{ma} 0205921$

[5] Trabelsi S., Albouy P-A., Rault J.: Crystallization and melting processes in vulcanized stretched natural rubber. Macromolecules, 36, 7624-7639 (2003).

DOI: $10.1021 / \mathrm{ma} 030224 \mathrm{c}$

[6] Toki S., Hsiao B. S.: Nature of strain-induced structures in natural and synthetic rubbers under stretching. Macromolecules, 36, 5915-5917 (2003).

DOI: $10.1021 / \mathrm{Ma} 034729 \mathrm{e}$

[7] Bergström J. S., Boyce M. C.: Mechanical behavior of particle filled elastomers. Rubber Chemistry and Technology, 72, 633-656 (1999).

DOI: $10.5254 / 1.3538823$

[8] Fukahori Y.: The mechanics and mechanism of the carbon black reinforcement of elastomers. Rubber Chemistry and Technology, 76, 548-566 (2003).

DOI: $10.5254 / 1.3547760$

[9] Rezende C. A., Bragança F. C., Doi T. R., Lee L-T., Galembeck F., Boué F.: Natural rubber-clay nanocomposites: Mechanical and structural properties. Polymer, 51, 3644-3652 (2010).

DOI: $10.1016 /$ j.polymer.2010.06.026

[10] Nie Y., Huang G., Qu L., Wang X., Weng G., Wu J.: New insights into thermodynamic description of straininduced crystallization of peroxide cross-linked natural rubber filled with clay by tube model. Polymer, 52, 3234-3242 (2011).

DOI: 10.1016/j.polymer.2011.05.004

[11] Chenal J-M., Gauthier C., Chazeau L., Guy L., Bomal Y.: Parameters governing strain induced crystallization in filled natural rubber. Polymer, 48, 6893-6901 (2007). DOI: 10.1016/j.polymer.2007.09.023

[12] Coleman J. N., Khan U., Blau W. J., Gun'ko Y. K.: Small but strong: A review of the mechanical properties of carbon nanotube-polymer composites. Carbon, 44, 1624 1652 (2006).

DOI: 10.1016/j.carbon.2006.02.038

[13] Zhu Y., Murali S., Cai W., Li X., Suk J. W., Potts J. R., Ruoff R. S.: Correction: Graphene and graphene oxide: Synthesis, properties, and applications. Advanced Materials, 22, 5226 (2010).

DOI: $10.1002 / \mathrm{adma} .201090156$

[14] Dikin D. A., Stankovich S., Zimney E. J., Piner R. D., Dommett G. H. B., Evmenenko G., Nguyen S. T., Ruoff R. S.: Preparation and characterization of graphene oxide paper. Nature, 448, 457-460 (2007). DOI: $10.1038 /$ Nature06016

[15] Bai X., Wan C., Zhang Y., Zhai Y.: Reinforcement of hydrogenated carboxylated nitrile-butadiene rubber with exfoliated graphene oxide. Carbon, 49, 1608-1613 (2011).

DOI: $10.1016 /$ j.carbon.2010.12.043
[16] Kang H., Zuo K., Wang Z., Zhang L., Liu L., Guo B.: Using a green method to develop graphene oxide/elastomers nanocomposites with combination of high barrier and mechanical performance. Composites Science and Technology, 92, 1-8 (2014).

DOI: 10.1016/j.compscitech.2013.12.004

[17] Moghaddam S. Z., Sabury S., Sharif F.: Dispersion of rGO in polymeric matrices by thermodynamically favorable self-assembly of GO at oil-water interfaces. RSC Advances, 4, 8711-8719 (2014). DOI: $10.1039 / \mathrm{c} 3 \mathrm{ra} 46342 \mathrm{~g}$

[18] Mao Y., Zhang S., Zhang D., Chan T. W., Liu L.: Enhancing graphene oxide reinforcing potential in composites by combined latex compounding and spray drying. Materials Research Express, 1, 025009/1025009/13 (2014).

DOI: $10.1088 / 2053-1591 / 1 / 2 / 025009$

[19] Wang Z., Liu J., Wu S., Wang W., Zhang L.: Novel percolation phenomena and mechanism of strengthening elastomers by nanofillers. Physical Chemistry Chemical Physics, 12, 3014-3030 (2010).

DOI: $10.1039 / \mathrm{b} 919789 \mathrm{c}$

[20] Khan U., May P., O’Neill A., Coleman J. N.: Development of stiff, strong, yet tough composites by the addition of solvent exfoliated graphene to polyurethane. Carbon, 48, 4035-4041 (2010). DOI: $10.1016 /$ j.carbon.2010.07.008

[21] Choi J. T., Kim D. H., Ryu K. S., Lee H-I., Jeong H. M., Shin C. M., Kim J. H., Kim B. K.: Functionalized graphene sheet/polyurethane nanocomposites: Effect of particle size on physical properties. Macromolecular Research, 19, 809-814 (2011).

DOI: $10.1007 / \mathrm{s} 13233-011-0801-4$

[22] Chatterjee S., Nafezarefi F., Tai N. H., Schlagenhauf L., Nüesch F. A., Chu B. T. T.: Size and synergy effects of nanofiller hybrids including graphene nanoplatelets and carbon nanotubes in mechanical properties of epoxy composites. Carbon, 50, 5380-5386 (2012). DOI: $10.1016 /$ j.carbon.2012.07.021

[23] Wang X., Jin J., Song M.: An investigation of the mechanism of graphene toughening epoxy. Carbon, $\mathbf{6 5}$, 324-333 (2013).

DOI: $10.1016 /$ j.carbon.2013.08.032

[24] Gojny F. H., Wichmann M. H. G., Fiedler B., Schulte $\mathrm{K}$. : Influence of different carbon nanotubes on the mechanical properties of epoxy matrix composites - A comparative study. Composites Science and Technology, 65, 2300-2313 (2005).

DOI: 10.1016/j.compscitech.2005.04.021

[25] Song Y. S., Youn J. R.: Influence of dispersion states of carbon nanotubes on physical properties of epoxy nanocomposites. Carbon, 43, 1378-1385 (2005). DOI: $10.1016 /$ j.carbon.2005.01.007

[26] Fu S-Y., Feng X-Q., Lauke B., Mai Y-W.: Effects of particle size, particle/matrix interface adhesion and particle loading on mechanical properties of particulate-polymer composites. Composites Part B: Engineering, 39, 933-961 (2008).

DOI: $10.1016 /$ j.compositesb.2008.01.002 
[27] Prolongo S. G., Jiménez-Suárez A., Moriche R., Ureña A.: Graphene nanoplatelets thickness and lateral size influence on the morphology and behavior of epoxy composites. European Polymer Journal, 53, 292-301 (2014).

DOI: 10.1016/j.eurpolymj.2014.01.019

[28] Tang Z., Zeng C., Lei Y., Guo B., Zhang L., Jia D.: Fluorescent whitening agent stabilized graphene and its composites with chitosan. Journal of Materials Chemistry, 21, 17111-17118 (2011). DOI: $10.1039 / \mathrm{C} 1 \mathrm{jm} 13239 \mathrm{c}$

[29] Lorenz O., Parks C. R.: The crosslinking efficiency of some vulcanizing agents in natural rubber. Journal of Polymer Science, 50, 299-312 (1961). DOI: $10.1002 /$ pol.1961.1205015404

[30] Zhang L., Liang J., Huang Y., Ma Y., Wang Y., Chen Y.: Size-controlled synthesis of graphene oxide sheets on a large scale using chemical exfoliation. Carbon, 47, 3365-3368 (2009).

DOI: $10.1016 /$ j.carbon.2009.07.045

[31] Khan U., O’Neill A., Porwal H., May P., Nawaz K., Coleman J. N.: Size selection of dispersed, exfoliated graphene flakes by controlled centrifugation. Carbon, 50, 470-475 (2012).

DOI: $\underline{10.1016 / \text { j.carbon.2011.09.001 }}$

[32] Wang X., Bai H., Shi G.: Size fractionation of graphene oxide sheets by $\mathrm{pH}$-assisted selective sedimentation. Journal of the American Chemical Society, 133, 63386342 (2011).

DOI: $10.1021 / \mathrm{ja} 200218 \mathrm{y}$

[33] Pan S., Aksay I. A.: Factors controlling the size of graphene oxide sheets produced via the graphite oxide route. ACS Nano, 5, 4073-4083 (2011).

DOI: $10.1021 / \mathrm{nn} 200666 \mathrm{r}$

[34] Zhou X., Liu Z.: A scalable, solution-phase processing route to graphene oxide and graphene ultralarge sheets. Chemical Communications, 46, 2611-2613 (2010). DOI: $10.1039 / \mathrm{b} 914412 \mathrm{a}$

[35] Zhao J., Pei S., Ren W., Gao L., Cheng H-M.: Efficient preparation of large-area graphene oxide sheets for transparent conductive films. ACS Nano, 4, 5245-5252 (2010).

DOI: $10.1021 / \mathrm{nn} 1015506$

[36] Aboutalebi S. H., Gudarzi M. M., Zheng Q. B., Kim JK.: Spontaneous formation of liquid crystals in ultralarge graphene oxide dispersions. Advanced Functional Materials, 21, 2978-2988 (2011). DOI: $10.1002 / \mathrm{adfm} .201100448$

[37] Lin X., Shen X., Zheng Q., Yousefi N., Ye L., Mai Y-W., Kim J-K.: Fabrication of highly-aligned, conductive, and strong graphene papers using ultralarge graphene oxide sheets. ACS Nano, 6, 10708-10719 (2012). DOI: $\underline{10.1021 / \mathrm{nn} 303904 \mathrm{z}}$
[38] Premanathan M., Karthikeyan K., Jeyasubramanian K., Manivannan G.: Selective toxicity of $\mathrm{ZnO}$ nanoparticles toward Gram-positive bacteria and cancer cells by apoptosis through lipid peroxidation. Nanomedicine: Nanotechnology, Biology and Medicine, 7, 184-192 (2011).

DOI: $10.1016 /$ j.nano.2010.10.001

[39] Potts J. R., Shankar O., Du L., Ruoff R. S.: Processingmorphology-property relationships and composite theory analysis of reduced graphene oxide/natural rubber nanocomposites. Macromolecules, 45, 6045-6055 (2012).

DOI: $10.1021 / \mathrm{ma3} 00706 \mathrm{k}$

[40] Potts J. R., Shankar O., Murali S., Du L., Ruoff R. S.: Latex and two-roll mill processing of thermally-exfoliated graphite oxide/natural rubber nanocomposites. Composites Science and Technology, 74, 166-172 (2013).

DOI: 10.1016/j.compscitech.2012.11.008

[41] Chen L., Pang X-J., Zhang Q-T., Yu Z-L.: Cutting of carbon nanotubes by a two-roller mill. Materials Letters, 60, 241-244 (2006).

DOI: 10.1016/j.matlet.2005.08.024

[42] Yue D., Liu Y., Shen Z., Zhang L.: Study on preparation and properties of carbon nanotubes/rubber composites. Journal of Materials Science, 41, 2541-2544 (2006). DOI: $10.1007 / \mathrm{s} 10853-006-5331-7$

[43] Krause B., Boldt R., Pötschke P.: A method for determination of length distributions of multiwalled carbon nanotubes before and after melt processing. Carbon, 49, 1243-1247 (2011).

DOI: 10.1016/j.carbon.2010.11.042

[44] Fu S-Y., Chen Z-K., Hong S., Han C. C.: The reduction of carbon nanotube (CNT) length during the manufacture of CNT/polymer composites and a method to simultaneously determine the resulting CNT and interfacial strengths. Carbon, 47, 3192-3200 (2009).

DOI: $10.1016 /$ j.carbon.2009.07.028

[45] Hernández M., del Mar Bernal M., Verdejo R., Ezquerra T. A., López-Manchado M. A.: Overall performance of natural rubber/graphene nanocompositefs. Composites Science and Technology, 73, 40-46 (2012). DOI: 10.1016/j.compscitech.2012.08.012

[46] Xing W., Wu J., Huang G., Li H., Tang M., Fu X.: Enhanced mechanical properties of graphene/natural rubber nanocomposites at low content. Polymer International, 63, 1674-1681 (2014). DOI: $10.1002 /$ pi.4689

[47] Ozbas B., Toki S., Hsiao B. S., Chu B., Register R. A., Aksay I. A., Prud'homme R. K., Adamson D. H.: Straininduced crystallization and mechanical properties of functionalized graphene sheet-filled natural rubber. Journal of Polymer Science Part B: Polymer Physics, 50, 718-723 (2012).

DOI: $10.1002 /$ polb.23060 
[48] Wang J., Jia H., Tang Y., Ji D., Sun Y., Gong X., Ding L.: Enhancements of the mechanical properties and thermal conductivity of carboxylated acrylonitrile butadiene rubber with the addition of graphene oxide. Journal of Materials Science, 48, 1571-1577 (2012).

DOI: $10.1007 / \mathrm{s} 10853-012-6913-1$

[49] Tang Z., Wu X., Guo B., Zhang L., Jia D.: Preparation of butadiene-styrene-vinyl pyridine rubber-graphene oxide hybrids through co-coagulation process and in situ interface tailoring. Journal of Materials Chemistry, 22, 7492-7501 (2012).

DOI: $10.1039 / \mathrm{c} 2 \mathrm{jm} 00084 \mathrm{a}$

[50] Zhao Y., Barrera E. V.: Asymmmetric diamino functionalization of nanotubes assisted by BOC protection and their epoxy nanocomposites. Advanced Functional Materials, 20, 3039-3044 (2010).

DOI: $10.1002 / \mathrm{adfm} .201000942$

[51] Affdl J. C. H., Kardos J. L.: The Halpin-Tsai equations: A review. Polymer Engineering and Science, 16, 344-352 (1976). DOI: $10.1002 /$ pen.760160512

[52] Mori T., Tanaka K.: Average stress in matrix and average elastic energy of materials with misfitting inclusions. Acta Metallurgica, 21, 571-574 (1973).

DOI: 10.1016/0001-6160(73)90064-3

[53] Potts J. R., Lee S. H., Alam T. M., An J., Stoller M. D., Piner R. D., Ruoff R. S.: Thermomechanical properties of chemically modified graphene/poly(methyl methacrylate) composites made by in situ polymerization. Carbon, 49, 2615-2623 (2011). DOI: $10.1016 /$ j.carbon.2011.02.023

[54] Ramanathan T., Abdala A. A., Stankovich S., Dikin D. A., Herrera-Alonso M., Piner R. D., Adamson D. H., Schniepp H. C., Chen X., Ruoff R. S., Nguyen S. T., Aksay I. A., Prud'homme R. K., Brinson L. C.: Functionalized graphene sheets for polymer nanocomposites. Nature Nanotechnology, 3, 327-331 (2008).

DOI: $10.1038 /$ nnano.2008.96

[55] Zhan Y., Wu J., Xia H., Yan N., Fei G., Yuan G.: Dispersion and exfoliation of graphene in rubber by an ultrasonically-assisted latex mixing and in situ reduction process. Macromolecular Materials and Engineering, 296, 590-602 (2011).

DOI: $10.1002 /$ mame.201000358

[56] Liao K-H., Aoyama S., Abdala A. A., Macosko C.: Does graphene change $T_{\mathrm{g}}$ of nanocomposites? Macromolecules, 47, 8311-8319 (2014).

DOI: $10.1021 / \mathrm{Ma} 501799 \mathrm{z}$

[57] Tang Z., Zhang L., Feng W., Guo B., Liu F., Jia D.: Rational design of graphene surface chemistry for highperformance rubber/graphene composites. Macromolecules, 47, 8663-8673 (2014).

DOI: $10.1021 / \mathrm{ma} 02201 \mathrm{e}$
[58] Vo L. T., Anastasiadis S. H., Giannelis E. P.: Dielectric study of poly(styrene-co-butadiene) composites with carbon black, silica, and nanoclay. Macromolecules, 44, 6162-6171 (2011). DOI: $10.1021 / \mathrm{ma} 200044 \mathrm{c}$

[59] Somaratne M. C. W., Liyanage N. M. V. K., Walpalage S.: Contribution of hydrogen and/or covalent bonds on reinforcement of natural rubber latex films with surface modified silica. Journal of Applied Polymer Science, 131, 40380/1-40380/9 (2014). DOI: $10.1002 /$ app. 40380

[60] Ramier J., Gauthier C., Chazeau L., Stelandre L., Guy L.: Payne effect in silica-filled styrene-butadiene rubber: Influence of surface treatment. Journal of Polymer Science Part B: Polymer Physics, 45, 286-298 (2007). DOI: $10.1002 /$ polb.21033

[61] Fröhlich J., Niedermeier W., Luginsland H-D.: The effect of filler-filler and filler-elastomer interaction on rubber reinforcement. Composites Part A: Applied Science and Manufacturing, 36, 449-460 (2005). DOI: 10.1016/j.compositesa.2004.10.004

[62] Che J., Burger C., Toki S., Rong L., Hsiao B. S., Amnuaypornsri S., Sakdapipanich J.: Crystal and crystallites structure of natural rubber and peroxide-vulcanized natural rubber by a two-dimensional wideangle X-ray diffraction simulation method. II. Straininduced crystallization versus temperature-induced crystallization. Macromolecules, 46, 9712-9721 (2013). DOI: $10.1021 / \mathrm{ma} 401812 \mathrm{~s}$

[63] Poompradub S., Tosaka M., Kohjiya S., Ikeda Y., Toki S., Sics I., Hsiao B. S.: Mechanism of strain-induced crystallization in filled and unfilled natural rubber vulcanizates. Journal of Applied Physics, 97, 103529/1103529/9 (2005).

DOI: $10.1063 / 1.1900927$

[64] Hernández M., Sanz A., Nogales A., Ezquerra T. A., López-Manchado M. A.: Structure and segmental dynamics relationship in natural rubber/layered silicate nanocomposites during uniaxial deformation. Macromolecules, 46, 3176-3182 (2013).

DOI: $10.1021 / \mathrm{ma} 4002353$

[65] Toki S., Sics I., Ran S. F., Liu L. Z., Hsiao B. S., Murakami S., Tosaka M., Kohjiya S., Poompradub S., Ikeda Y., Tsou A. H.: Strain-induced molecular orientation and crystallization in natural and synthetic rubbers under uniaxial deformation by in-situ synchrotron X-ray study. Rubber Chemistry and Technology, 77, 317-335 (2004). DOI: $10.5254 / 1.3547826$

[66] Qu L., Huang G., Liu Z., Zhang P., Weng G., Nie Y.: Remarkable reinforcement of natural rubber by deformation-induced crystallization in the presence of organophilic montmorillonite. Acta Materialia, 57, 50535060 (2009).

DOI: $10.1016 /$ j.actamat.2009.07.007 